\title{
Research on the Index System of Ship Safety Evaluation during the Storm
}

\author{
Xiuping Sui \\ Shandong Jiaotong University, Shandong, China \\ WHSUI@163.com
}

Keywords: AHP; ship safety evaluation; during the storm

\begin{abstract}
In order to improve the safety of the ship in the storm, this paper analyzes the impact of the storm weather on the ship's safety, and puts forward the response measures for the ship to sail in the gale wave, in order to help the ship in the storm safe navigation.
\end{abstract}

\section{Introduction}

During the storm, the ships are caused by the combined effects of wave force and wind force, and the ships sailing in it are shaken and rocking seriously. When the inclination angle of the ship is greater than the angle of the deck immersion, the deck of the ship will rise. Due to the increase in vertical swing and longitudinal shaking during sailing in large storms, the ship's spiral rotor will frequently expose the water surface, and the depth ratio of the propeller will be greatly reduced, resulting in a decrease in fluid resistance around the propeller, an increase in speed, and vibration. The so-called speed phenomenon. The ship's resistance will increase greatly in the storm, and the propeller's speed effect will lead to a significant reduction in the speed of the ship compared to the speed of the static water. Under a certain state of power, the more serious the speed reduction, the greater the load of the host. In order to protect the ship's host, the ship has to reduce the engine speed, thus increasing the overall transportation costs. The freedom of movement of the ship in the storm is greatly accelerated. When the acceleration of the movement exceeds the range that the ear cavity can withstand in the person's body, seasickness will occur. Under seasickness, the crew's behavioral ability will be greatly reduced and the body function will be reduced.. It affects the normal operation of the work.

No matter which sea area the ship is sailing in, the conditions for navigation can not be avoided. The navigation conditions of the storm waves are a great threat to the navigation safety of ships.

\section{Analytic Hierarchy Process}

Analytic hierarchy process is an analytical method combining qualitative analysis with quantitative analysis. The principle is to decompose complex problems into several levels and factors, make comparative judgment on the importance of the two indicators and establish judgment matrix. Through calculation of the judgment matrix eigenvalues and corresponding eigenvectors, the largest the degree of importance weights to different schemes are obtained and provide important basis for the selection of optimal: 


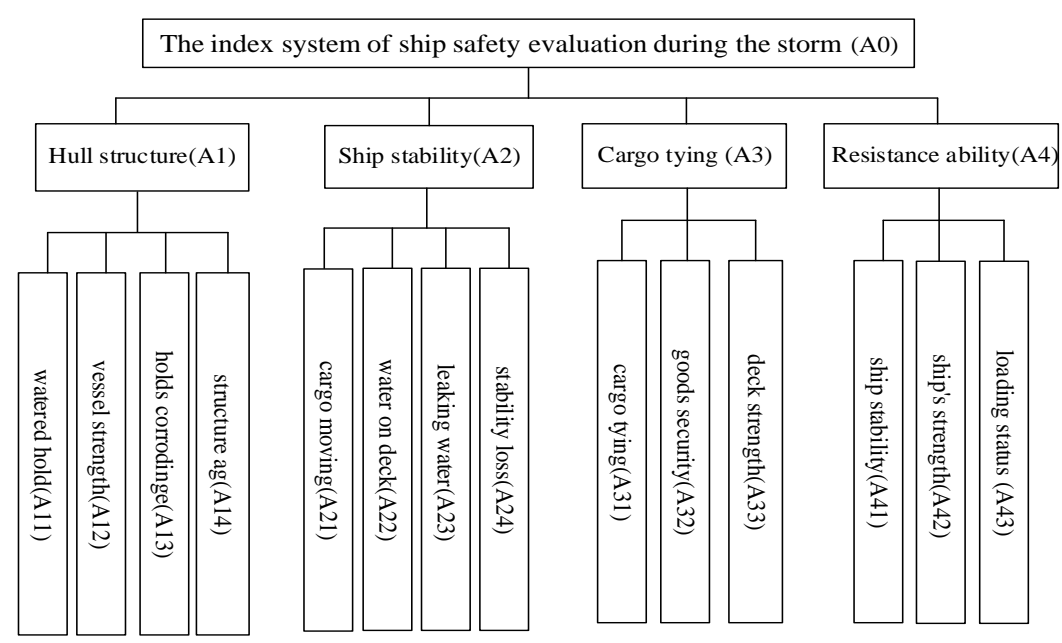

Figure 1. Index System of Ship Safety Evaluation

\section{Construct the Judgment Matrix}

Construct the judgment matrix and list $\mathrm{x}$ influencing factors respectively, forming an $\mathrm{x}$-order $\mathrm{A}=(\mathrm{x}) .$, ,... Each factor is compared in importance by a binary combination. $\mathrm{X}$ - order matrix each row matrix port; denotes the degree of importance of one factor to the rest of each factor; Similarly, for each column of moments, i represents the degree to which other factors are relevant to the same factor. According to the judgment matrix criterion, the relative importance and degree of importance of any two factors under the same criterion are compared by referring to the expert consultation and theoretical derivation, and according to the actual situation of the project, the importance degree of influencing factors is determined by assigning the number 1-9 logical relation according to the degree of importance.

\begin{tabular}{|l|l|l|l|l|}
\hline $\mathrm{A} 0$ & $\mathrm{~A} 1$ & $\mathrm{~A} 2$ & $\mathrm{~A} 3$ & $\mathrm{~A} 4$ \\
\hline $\mathrm{A} 1$ & 1.0000 & 0.3333 & 0.2500 & 0.2500 \\
\hline $\mathrm{A} 2$ & 3.0000 & 1.0000 & 0.5000 & 1.0000 \\
\hline $\mathrm{A} 3$ & 4.0000 & 2.0000 & 1.0000 & 2.0000 \\
\hline $\mathrm{A} 4$ & 4.0000 & 1.0000 & 0.5000 & 1.0000 \\
\hline
\end{tabular}

The result of calculation is as follow:

\section{$\mathrm{CI}=\mathbf{0 . 0 1 5 3} \quad \mathrm{CR}=\mathbf{0 . 0 1 7 0}$}

The contrast matrix A4 passes the consistency test, and each vector weight vector $\mathrm{W}$ is:
$\mathrm{W}=(\mathbf{0 . 0 8 1 8}$
0.2346
0.4288 0.2548) $\quad \lambda_{\max }=$
4.0458

\begin{tabular}{|l|l|l|l|l|}
\hline A1 & A11 & A12 & A13 & A14 \\
\hline A11 & 1.0000 & 2.0000 & 2.0000 & 0.5000 \\
\hline A12 & 0.5000 & 1.0000 & 0.5000 & 0.5000 \\
\hline A13 & 0.5000 & 2.0000 & 1.0000 & 1.0000 \\
\hline A14 & 2.0000 & 2.0000 & 1.0000 & 1.0000 \\
\hline
\end{tabular}


The result of calculation is as follow:

\section{$\mathrm{CI}=\mathbf{0 . 0 6 1 8} \quad \mathrm{CR}=\mathbf{0 . 0 6 8 7}$}

The contrast matrix A1 passes the consistency test, and each vector weight vector $\mathrm{W}$ is:
$\mathrm{W}=(\mathbf{0 . 2 8 7 3}$
$\mathbf{0 . 1 3 5 7}$
0.2370
0.3400 ) $\lambda_{\max }=\mathbf{4 . 1 8 5 5}$

\begin{tabular}{|l|l|l|l|l|}
\hline A2 & A21 & A22 & A23 & A24 \\
\hline A21 & 1.0000 & 0.3333 & 0.5000 & 3.0000 \\
\hline A22 & 3.0000 & 1.0000 & 0.5000 & 2.0000 \\
\hline A23 & 2.0000 & 0.2000 & 1.0000 & 1.0000 \\
\hline A24 & 0.3333 & 0.5000 & 1.0000 & 1.0000 \\
\hline
\end{tabular}

The result of calculation is as follow:

\section{$\mathrm{CI}=\mathbf{0 . 0 2 3 4} \quad \mathrm{CR}=\mathbf{0 . 0 2 6 0}$}

The contrast matrix A2 passes the consistency test, and each vector weight vector $\mathrm{W}$ is:
$\mathrm{W}=(\mathbf{0 . 2 3 5 6}$
0.3728
0.2303
0.1613) $\lambda_{\max }=$
4.0701

\begin{tabular}{|l|l|l|l|}
\hline A3 & A31 & A32 & A33 \\
\hline A31 & 1.0000 & 3.0000 & 2.0000 \\
\hline A32 & 0.3333 & 1.0000 & 1.0000 \\
\hline A33 & 0.5000 & 1.0000 & 1.0000 \\
\hline
\end{tabular}

The result of calculation is as follow:

$\mathrm{CI}=0.0091 \quad \mathrm{CR}=\mathbf{0 . 0 1 5 7}$

The contrast matrix A3 passes the consistency test, and each vector weight vector $\mathrm{W}$ is:

$\mathrm{W}=\left(\begin{array}{lll}\mathbf{0 . 5 4 9 9} & \mathbf{0 . 2 0 9 8} & \mathbf{0 . 2 4 0 2}\end{array}\right) \quad \lambda_{\max }=\mathbf{3 . 0 1 8 3}$

\begin{tabular}{|l|l|l|l|}
\hline A4 & A41 & A42 & A43 \\
\hline A41 & 1.0000 & 4.0000 & 2.0000 \\
\hline A42 & 0.2500 & 1.0000 & 1.0000 \\
\hline A43 & 0.5000 & 1.0000 & 1.0000 \\
\hline
\end{tabular}

The result of calculation is as follow:

\section{$\mathrm{CI}=\mathbf{0 . 0 2 6 8} \quad \mathrm{CR}=\mathbf{0 . 0 4 6 2}$}

The contrast matrix A3 passes the consistency test, and each vector weight vector $\mathrm{W}$ is:

$\mathrm{W}=\left(\begin{array}{lll}0.5842 & 0.1840 & 0.2318\end{array}\right) \quad \lambda_{\max }=3.0536$

There are 4 first class indicators including hull structure, ship stability:, cargo tying, resistance ability, ship stability is more important. Among hull structure, vessel strength is more important. Among ship stability, stability loss is important. Among cargo tying, goods security is a little important. Among resistance ability, ship stability is important.

\section{Conclusion}

When a ship is sailing in a big storm, it will experience waves on the deck, attacks, reduced propulsion efficiency, and severe shaking. In order to improve the safety of ships in stormy weather, The ship must make adequate preparations before entering the storm zone. After entering the storm 
zone, it must choose a reasonable method of sailing. After leaving the storm zone, it must promptly inspect the ship's condition and make a total conclusion.

\section{Reference}

[1] Marco T, Tiziana R, Claudia C. Being Social for Social:A Co-creation Perspective. Journal of Service Theory and Practice, 2015,25(2), pp.198-219.

[2] Assaf AG, Barros C, Sellers-Rubio R. Efficiency determinants in retail stores: A Bayesian framework. Omega. 2011, 39(3), pp.283-292.

[3] Roberto Linares, Jo Choi-Nurvitadhi,Svetlana Cooper, YoungYoon Ham, Jane E. Ishmael, Ann Zweber. Personnel training and patient education in medical marijuana dispensaries in Oregon. Journal of the American Pharmacists Association, 2016(12), pp.270-273.

[4] Dingyuemin. Research on the Evaluation Method of Personnel Quality Based on Medical Personnel Competence Model. Human Resources Management, 2015(2), pp.195-196.

[5] Feng D Y. On the Seafarer's Training of the Transitional Period of Implementing the STCW 78/10Convention. Journal of Qingdao Ocean Shipping Mariners College, 2013.

[6] Frederic P, Philipp K, Roger S. Experience Co-creation in Financial Services:An Empirical Exploration. Journal of Service Management, 2015, 26 (2), pp.295-320.

[7] Yu Huixian. Recruitment Based on Competency Model[J].Chinese and Foreign Exchanges, 2017,(17): 30 